\title{
Time-dependent inhibition of insulin release: glucose-arginine interactions in the perfused rat pancreas
}

\author{
R. Nesher, L. Waldman and E.Cerasi \\ Department of Endocrinology and Metabolism, The Hebrew University Hadassah Medical Center, Jerusalem, Israel
}

\begin{abstract}
Summary. The isolated perfused rat pancreas was stimulated sequentially with arginine or glucose to analyze the time-dependent modulation of insulin release. A 10-min perfusion with arginine $(5.0 \mathrm{mmol} / 1)$ induced $75 \%$ inhibition of the insulin response to repeated arginine stimulation $10 \mathrm{~min}$ later. When glucose $(8.3 \mathrm{mmol} / \mathrm{l})$ was given as two pulses, inhibition of the second insulin response was less pronounced. The inhibitory effect generated by arginine also suppressed the insulin response to glucose $(27.7 \mathrm{mmol} / \mathrm{l})$, and this inhibitory effect persisted for over $80 \mathrm{~min}$. Stimulation for $30 \mathrm{~min}$ with glucose $(27.7 \mathrm{mmol} / \mathrm{l})$ strongly potentiated the insulin responses to a pair of arginine stimuli given $20 \mathrm{~min}$ later. However, despite augmented secretion rates, the insulin response to the second arginine pulse was still inhibited by $75 \%$. When insulin secretion was strongly amplified by two $10 \mathrm{~min}$ pulses of the synergistic mixture of arginine $(5.0 \mathrm{mmol} / 1)$ and glucose $(8.3 \mathrm{mmol} / \mathrm{l})$, there was no inhibition of the second insulin response. If glucose $(8.3 \mathrm{mmol} / \mathrm{l})$ was present during the first ar-
\end{abstract}

ginine stimulation only, the response to the second arginine pulse was inhibited as in control experiments. However, when glucose was added to the second arginine pulse only, the inhibition generated by the first arginine pulse did not express itself, insulin release remaining similar to control. We conclude that: (1) short stimulations of the pancreas by arginine or glucose generate long-lasting inhibition of the insulin response to subsequent stimulations; (2) synergistic amplification of the insulin response by addition of glucose to arginine obliterates the inhibition; (3) glucose does not suppress the induction of inhibition, it blocks the expression of the inhibitory signal on insulin secretion; (4) these in vitro findings are in keeping with observations in normal and hyperglycaemic man.

Key words: Perfused pancreas, insulin secretion, arginine, synergism, time-dependent inhibition, time-dependent potentiation.
Studies in vivo and in vitro have demonstrated that the insulin secretion rate is modified by prior sensitization of the pancreas to various insulin releasers [1-10]. While some stimulators like glucose may generate either a state of potentiation or inhibition in the islet according to the conditions of exposure $[2,3,8]$, arginine induces only an inhibitory state [3,11].

The inhibitory state generated by prior exposure to glucose or arginine, termed time-dependent inhibition (TDI), has so far been described only in vivo. In an accompanying paper [11] we demonstrated that it was absent in moderately or slightly hyperglycaemic man (non-insulin-dependent diabetes and obesity), and could be abolished in normal subjects by the acute induction of hyperglycaemia. Since arginine and glucose administration in vivo lead to complex modifications in the milieu of the B cell, and since plasma levels of insulin give only an indirect measure of the insulin secretion rate, the perfused rat pancreas was used to quantify the
TDI generated by arginine, and characterize its modification by interactions with glucose.

\section{Materials and methods}

Fed male Sabra rats (Hebrew University Animal Farm, Jerusalem, Israel) weighing $200-250 \mathrm{~g}$ were used. They were anaesthetized by IP injection of $100 \mathrm{mg} / \mathrm{kg}$ thiopentone sodium. The pancreas was isolated completely and perfused at $37^{\circ} \mathrm{C}$ via the abdominal aorta with Krebs-Ringer bicarbonate buffer containing $\mathrm{CaCl}_{2}(1.25 \mathrm{mmol} / 1)$, bovine serum albumin $(2.0 \%)$, glucose $(3.3 \mathrm{mmol} / \mathrm{l})$, and gassed with $\mathrm{O}_{2}: \mathrm{CO}_{2}(95 \%: 5 \%)$. Perfusion pressure was maintained by means of an adjustable pressure head and the flow kept at $2.5 \mathrm{ml} / \mathrm{min}$. Experiments were initiated after a $30 \mathrm{~min}$ basal perfusion. When indicated, the perfusion was changed to a parallel system (dead volume $0.1 \mathrm{ml}$ ) for stimulatory pulses with buffer containing arginine and/or glucose. Insulin (IRI) was determined in the perfusate by radioimmunoassay using rat insulin standard (Novo Research Institute, Bagsvaerd, Denmark).

Statistical analyses were performed using two-tailed paired Student's t-test. Results are expressed as mean \pm SEM. 

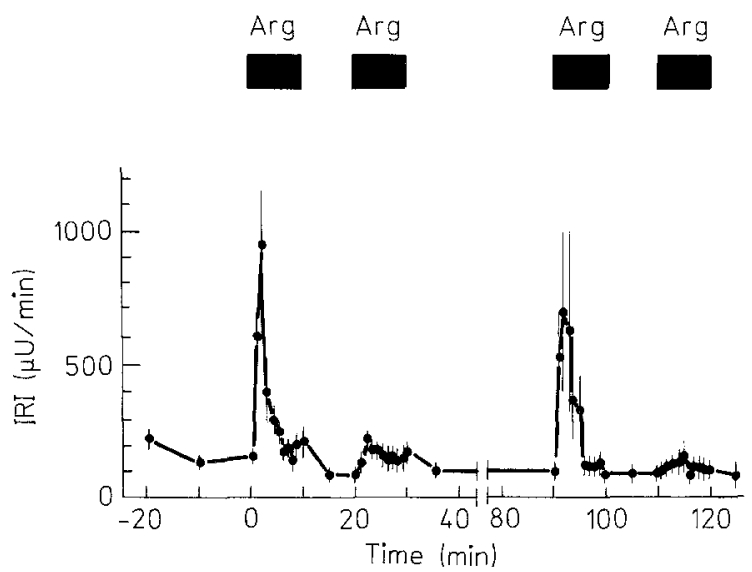

Fig. 1. Arginine-induced time-dependent inhibition of immunoreactive insulin (IRI) release in vitro. The isolated perfused rat pancreas was subjected to repeated pairs of 10 -min arginine (Arg) stimuli $(5.0 \mathrm{mmol} / \mathrm{l})$ separated by 10 -min perfusion with basal glucose $(3.3 \mathrm{mmol} / \mathrm{l})$. Results are mean \pm SEM of four experiments

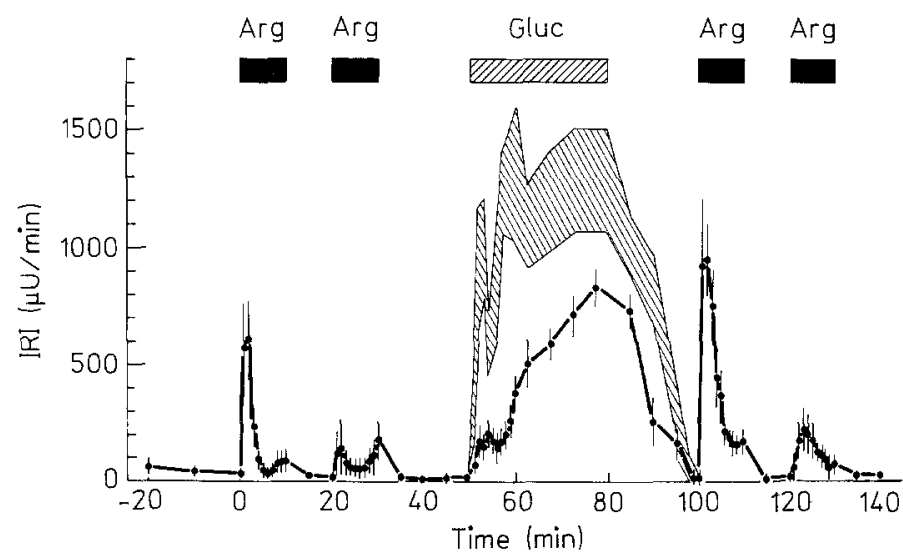

Fig. 2. Time-dependent inhibition of immunoreactive insulin (IRI) release induced by arginine following time-dependent potentiation induced by glucose. The isolated rat pancreas was subjected to a pair of $10 \mathrm{~min}$ stimuli with arginine (Arg, $5.0 \mathrm{mmol} / \mathrm{l}$ ) before and after a 30 - min infusion of glucose (Gluc, $27.7 \mathrm{mmol} / \mathrm{l}$ ). The shaded area represents control stimulations with glucose $(27.7 \mathrm{mmol} / 1)$ not preceded by arginine infusion. Basal glucose concentration was $3.3 \mathrm{mmol} / \mathrm{I}$. Results are mean \pm SEM of five experiments

\section{Results}

To demonstrate TDI the pancreas was stimulated with a pair of $10 \mathrm{~min}$ perfusions of arginine $(5.0 \mathrm{mmol} / \mathrm{l})$ in the presence of basal glucose $(3.3 \mathrm{mmol} / \mathrm{l})$ at an interval of 10 min. Figure 1 and Table 1 show that the insulin response to the second stimulation was inhibited by $75 \%$. When the pancreas was subjected to an additional pair of stimuli with arginine after $60 \mathrm{~min}$, a TDI of the same magnitude was observed; the peak insulin secretion rate during the third stimulus was however somewhat lower than during the first, indicating that the inhibitory effect generated by the first pair of arginine infusions had not entirely disappeared (Fig. 1). When 10-min stimulations with glucose $(8.3 \mathrm{mmol} / \mathrm{l})$ were used instead of arginine, peak insulin secretion was inhibited by $30 \%$ during the second stimulus; however no effect could be demonstrated on the total amount of hormone released (Table 1).

Prolonged stimulation with glucose potentiates subsequent insulin responses. To investigate whether glucose-induced potentiation could abolish the arginineinduced TDI, a $30 \mathrm{~min}$ glucose stimulation $(27.7 \mathrm{mmol} / \mathrm{l})$ was introduced between two pairs of arginine pulses. As shown in Figure 2, the third arginine-induced insulin response was augmented by $300 \%$. However, the insulin response to the subsequent arginine stimulus was inhibited to the same extent as during the control arginine pair ( 77 and 79\%, respectively). Thus, glucose-induced potentiation did not influence the inhibitory effect of arginine. Figure 2 also shows that the inhibition generated by the first pair of arginine infusions blunted the insulin response to glucose given $20 \mathrm{~min}$ later ( $88 \%$ inhibition of first phase, $55 \%$ of second phase).

When the perfused pancreas was stimulated by two consecutive $10 \mathrm{~min}$ periods of a mixture of the two secretagogues $(5.0 \mathrm{mmol} / 1$ arginine with $8.3 \mathrm{mmol} / 1 \mathrm{glu}$ cose) the inhibitory effect of arginine on insulin release was almost abolished, while a strong synergistic effect
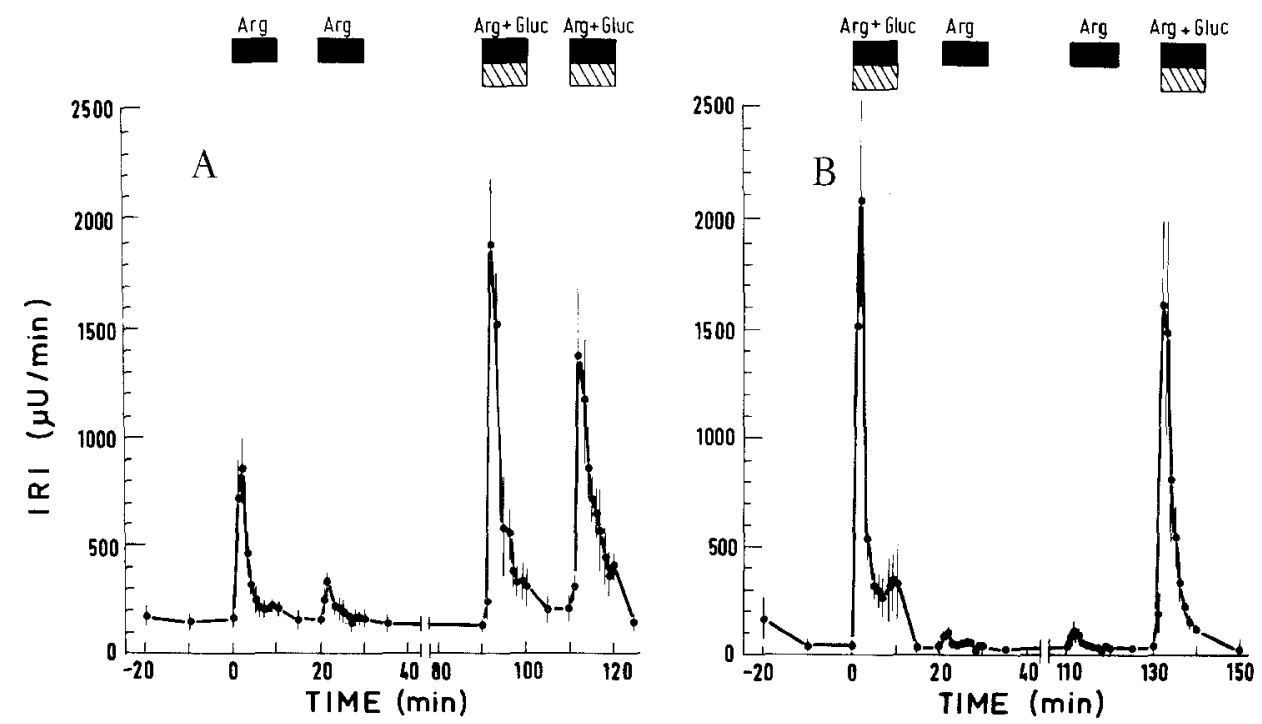

Fig.3. Abolition of arginine-induced time-dependent inhibition by glucose. (A) Effect of arginine alone (first pair), and addition of glucose $(8.3 \mathrm{mmol} / \mathrm{l})$ to both arginine pulses (second pair). (B) Selective effect of glucose. In the first pair of stimulations, glucose $(8.3 \mathrm{mmol} / \mathrm{l})$ was added to the first arginine $(5.0 \mathrm{mmol} / \mathrm{l})$ pulse only; in the second pair glucose was present during the second arginine pulse only. Results are mean \pm SEM of two sets of five experiments each. IRI $=$ Immunoreactive insulin 
Table 1. Interaction between glucose and arginine on insulin release from the perfused rat pancreas

\begin{tabular}{lcc}
\hline Stimulus & $\begin{array}{l}\text { Total IRI } \\
(\mathrm{mU} / 10 \mathrm{~min})\end{array}$ & $\begin{array}{c}\text { Peak IRI } \\
(\mathrm{mU} / \mathrm{min})\end{array}$ \\
\hline Arginine no. $1(n=15)$ & $1.75 \pm 0.27$ & $0.76 \pm 0.13$ \\
Arginine no. $2(n=15)$ & $0.47 \pm 0.09$ & $0.19 \pm 0.05$ \\
$2 / 1$ & 0.27 & 0.25 \\
$p$ & $<0.005$ & $<0.005$ \\
Glucose no. 1 $(n=5)$ & $1.79 \pm 0.56$ & $0.80 \pm 0.27$ \\
Glucose no. 2 $(n=5)$ & $1.72 \pm 0.49$ & $0.55 \pm 0.15$ \\
$2 / 1$ & 0.96 & 0.69 \\
$p$ & $\mathrm{NS}$ & $<0.05$ \\
Arginine+ glucose no. 1 & $5.11 \pm 1.68$ & $1.90 \pm 0.67$ \\
$\quad(n=5)$ & & $1.23 \pm 0.30$ \\
Arginine+ glucose no. 2 & $4.24 \pm 1.25$ & \\
$(n=5)$ & & 0.65 \\
$2 / 1$ & 0.83 & $\mathrm{NS}$ \\
$p$ & $\mathrm{NS}$ & \\
\hline
\end{tabular}

Results expressed as mean \pm SEM

on insulin secretion was observed (Fig. $3 \mathrm{~A}$ and Table 1). Figure $3 \mathrm{~B}$ shows that addition of glucose only to the first arginine pulse, while demonstrating a marked synergistic effect on insulin release, did not prevent the inhibition of the response to the second arginine pulse. When the order of stimulation was reversed and glucose added only to the second arginine pulse, the inhibitory effect of arginine on insulin release was completely abolished. The insulin response to the third arginine (alone) infusion was still suppressed, reflecting the remaining inhibitory effect of the first pair of infusions.

These results were also used to evaluate quantitative aspects of the synergism between glucose and arginine. When the insulin response to arginine $(5.0 \mathrm{mmol} / 1)$ + glucose $(8.3 \mathrm{mmol} / \mathrm{l})$ was compared to the sum of the responses to arginine and glucose given separately, the arginine-glucose synergism resulted in an increase of $150 \%$ in total insulin secretion and of $122 \%$ in peak insulin release for the initial stimuli, and of $194 \%$ and $216 \%$ respectively for the second pair of stimuli.

\section{Discussion}

We $[1-4,8,10,11]$ and others [5-7, 9] have shown that many agents which stimulate the acute release of insulin also modify the responsiveness of the islet for a considerable time, resulting in either potentiation or inhibition of subsequent insulin responses. We have termed these effects time-dependent potentiation and inhibition (TDI), respectively.

Arginine induces exclusively TDI [3]. Previous studies examining TDI were performed in vivo; the present report demonstrates that in the perfused pancreas, completely isolated from adjacent organs and disconnected from its nerves, a 10-min stimulation with a relatively low arginine concentration $(5 \mathrm{mmol} / \mathrm{l})$ markedly reduces the insulin responsiveness for considerable time. The maximal effect, approximately $75 \%$ inhibition, was recorded $10 \mathrm{~min}$ after the end of the priming arginine infusion, some degree of inhibition remaining for up to $80 \mathrm{~min}$. This persistence of the TDI signal in vitro is in accordance with findings in healthy volunteers given two arginine infusions [3]. Priming with arginine inhibited insulin release elicited either by arginine or glucose (Fig. 2). This suggests that the inhibitory message generated by arginine is non-specific in its expression, so that the insulin response to any agent may be inhibited. In that respect it is similar to time-dependent potentiation which also lacks specificity, the insulin response to all agents being potentiated following priming with for example glucose $[8,12]$.

We show, in an accompanying paper [11], that chronic hyperglycaemia of moderate or of minimal degree, as well as moderate hyperglycaemia induced acutely by glucose infusion in healthy volunteers, obliterates the TDI generated by arginine. The present study shows that this action of glucose is a direct one on the pancreas. The interactions of glucose with arginine seem to be complex. That the two agents given together act synergistically and amplify insulin release is well known. We have shown here, as previously in vivo [3, 10], that TDI can also be induced by glucose, albeit to a lesser extent than by arginine. On consecutive stimulations the second insulin response both to arginine and to glucose was diminished, so the sum of the responses to the two agents given together might be expected to show a similar inhibition. Since this was not the case, we conclude that the synergistic interaction of glucose with arginine blocks TDI. Glucose can amplify the insulin response by another mechanism, namely time-dependent potentiation (Fig. 2). However, even in this amplified state the insulin response to the second arginine pulse remained inhibited. This leads us to conclude that amplification of the insulin response to arginine when glucose is present in the perfusate has a different mechanism from the amplification generated by pre-exposure to glucose.

The presence of glucose apparently does not prevent the generation of an inhibitory message by arginine since when glucose was added to the first arginine pulse only, the second insulin response remained inhibited (Fig. 3B). The mixture of glucose-arginine may even further enhance the generation of TDI, as demonstrated by the strong inhibition of the insulin response to arginine given as a third pulse at 110 min (compare Figs. 1 and $3 \mathrm{~B}$ ). Glucose however seems to block the expression of the inhibitory message generated by arginine, since when added only to the second arginine perfusion, the full insulin response was restored. Clarification of the mechanism by which glucose interferes with the effectuation of TDI action must await further investigation. 
Acknowledgments. The authors wish to thank M. Pick and G. Lebedeva for performing the insulin assays and L. Granot for assistance in manuscript preparation. This work was supported in part by Grant No. R01 AM 21598 from the National Institutes of Health, a grant from the Juvenile Diabetes Foundation, and a grant from the Israel Ministry of Health, Chief Scientist's Office.

\section{References}

1. Cerasi E, Fick G, Rudemo M (1974) A mathematical model for the glucose induced insulin release in man. Eur J Clin Invest 4: 267-278

2. Cerasi E (1975) Potentiation of insulin release by glucose in man. I. Quantitative analysis of the enhancement of glucose-induced insulin secretion by pretreatment with glucose in normal subjects. Acta Endocrinol (Copenh) 79: 483-501

3. Efendic S, Lins PE, Cerasi E (1979) Potentiation and inhibition of insulin release in man following priming with glucose and with arginine - effect of somatostatin. Acta Endocrinol (Copenh) 90: $259-271$

4. Cerasi $E$ (1981) Differential actions of glucose on insulin release: recvaluation of a mathematical model. In: Cobelli C, Bergman RN (eds) Carbohydrate metabolism. John Willey and Sons, New York, pp 3-24

5. Curry DL, Bennett LL, Grodsky GM (1968) Dynamics of insulin secretion by the perfused rat pancreas. Endocrinology 83: $572-584$

6. Grodsky GM (1972) A threshold distribution hypothesis for packet storage of insulin and its mathematical modeling. J Clin Invest $51: 2057-2059$
7. O'Connor MDL, Landahl H, Grodsky GM (1980) Comparison of storage and signal limited models of pancreatic insulin secretion. Am J Physiol 238: R378-R389

8. Grill V, Adamson U, Cerasi E (1978) Immediate and time-dependent effects of glucose on insulin release from rat pancreatic tissue. Evidence for different mechanisms of action. J Clin Invest 61: 1034-1043

9. Ashby JP, Shirling D (1980) Evidence for priming and inhibitory effects of glucose on insulin secretion from isolated islets of Langerhans. Diabetologia 18: 417-421

10. Cerasi E (1975) Feedback inhibition of insulin secretion in subjects with high and low insulin response to glucose. Diabete Metab 1: $73-76$

11. Nesher R, Tuch T, Hage C, Levy J, Cerasi E (1984) Time-dependent inhibition of insulin release: suppression of arginine effect by hyperglycaemia. Diabetologia 26: 142-146

12. Cerasi E (1975) Potentiation of insulin release by glucose in man. II. Role of the insulin response and enhancement of stimuli other than glucose. Acta Endocrinol (Copenh) 79: 502-510

Received: 17 February 1983

and in revised form: 5 September 1983

Dr. Rafael Nesher

Department of Endocrinology and Metabolism

Hadassah Medical Center

P.O. Box 12000

91120 Jerusalem, Israel 